\title{
Adaption of Different Operation Strategies for a Sequencing Batch Reactor Plant Working at Seasonal Load Variations
}

\author{
Alexandra Bercoff and Stig Morling* \\ Sweco Environment AB, P.O. Box 34044, Se 10026 Stockholm, Sweden
}

Received: December 18, 2013 / Accepted: January 15, 2014

\begin{abstract}
A small SBR-plant (Sequencing Batch Reactor) operating at substantial load variations has been examined with respect to performance at changing load conditions. The plant serves a ski resort area about $200 \mathrm{~km}$ north of Stockholm. The plant has a capacity equivalent to 700 pe and a daily flow of 100 $\mathrm{m}^{3} / \mathrm{d}$. The results have been examined closely both by a one year follow-up study of the plant performance and also by a Master Thesis. The analysis of the performance study demonstrates how flexible an intermittently operated biological reactor is in treating varying loads, but also indicates possible operational strategies. It is important to keep in mind that the inlet concentrations of the main pollutants far exceed the "normal" values in untreated municipal wastewater. This circumstance is mainly attributed to a new and concentrated sewer system. Thus the amounts of diluting water are very limited.

The treatment chain is built up by a pre-treatment stage, a biological and chemical treatment stage in an SBR-reactor and a final polishing stage where the water passes a fine grade screening filter.

The requirements set for effluent water by the Environmental Protection Division on the Environmental Testing Advisory Board at the Swedish Environmental Agency are:

- $\mathrm{BOD}_{7}<10$ ppm;

- Total $P<0.3$ ppm;

No formal requirements have been addressed for COD, suspended solids (SS) or nitrogen. However, these pollution indicators have also been examined during the follow-up session. Typical performance results during the intense period (ski season) were as follows:
\end{abstract}

*Corresponding author: stig.morling@sweco.se
- $\mathrm{BOD}_{7}<3$ ppm, equivalent to a removal efficiency of around $99 \%$;

- $C O D<40 \mathrm{ppm}$, equivalent to a removal efficiency of around $96 \%$;

- SS $<5$ ppm, equivalent to a removal efficiency of around $99 \%$;

- Total $\mathbf{P}<0.3$ ppm, equivalent to a removal efficiency of around $98 \%$; and

- Total $\mathbf{N}<\mathbf{4 0}$ ppm, equivalent to a removal efficiency of around $77 \%$.

Abbreviations: $\mathrm{BOD}_{7}$ means Biochemical Oxygen Demand measured during 7 days; COD means Chemical Oxygen Demand; SS means Suspended Solids, as captured on a filter with 0,45mm; SRT means Solids Residence Time.

Keywords: Nitrogen, phosphorus, nitrification, SBR, load variations, process adaption.

\section{Introduction}

Safeguarding the water environment adjacent to resorts is often crucial as water bodies in these areas often are sensitive and may be harmed by effluent water. Furthermore, with the substantial variation of the pollution loading have the environmental impact is to be considered. There are a number of technical solutions to safeguard good water environment protection. SBR-technology was introduced in the 1970s, mainly in the United States. Treating wastewater from resort areas, with typically steep weekly pollution variations was an early application of the technology, see Barth (1981). Further support for an intermittent loading of the SBR-system was given by Schroeder et al (1986) in laboratory scale studies. These studies demonstrated that the SBR-technology is capable of operating with 
idle phases of 17 hours.

Indeed, SBR-technology has attained considerable popularity among "turn-key" contractors focusing on small plant units. However, since the fundamental findings in the 1970s and 1980s, the collections of performance data and intensified process control of small SBR-plants have been rather few. This is easily explained by the following reasons:

- Limited budgets for follow up studies;

- Often remote location of the plants;

- Lack of further interest of process development.

In 1991 the Gällivare municipality along with the Technical University of Luleå conducted a study lasting for over one year at a small, conventional activated sludge plant that had been converted into an SBR unit. The specific aim of the study was to examine the possibilities for biological phosphorus removal when operating an intermittent plant at low water temperature, Marklund and Morling (1994). The results showed that it is possible to operate an SBR-plant at low water temperatures, down to around $4^{\circ} \mathrm{C}$, with good results. The need for adjustment of the SBR operation cycle was found evident, as the temperature varied from 3.5 to $10^{\circ} \mathrm{C}$. As an example, the needed settling time for sludge separation was doubled when the temperature lowered from $10^{\circ} \mathrm{C}$ to $4^{\circ} \mathrm{C}$. Accordingly, comprehensive experiences from SBR-operation on leachate water have demonstrated the process "built in" capacity to meet strong variations in both loading and water temperatures, Morling (2010).

The intermittent operation mode is not refined to an SBRsystem. Various technical activated sludge systems are in fact based on this mode, ever since Dr Pasveer (1959) introduced the Oxidation Ditch system in the1950s. Today, well known models, such as the CASS system and the Biodenitro model, are based on typically intermittent operation modes. Furthermore, the intermittent operation mode may be adopted in a continuous flow system at low loading conditions. A recent example has been presented by Berg and Morling (2013) describing an activated sludge plant in Sri Lanka initially operated at around $10 \%$ of the design capacity. The introduction of an intermittent mode particularly improved the total nitrogen removal and created favourable conditions for an enhanced biological phosphorus removal.

This study's first objective is to present and analyse the plant compliance with the stipulated consent discharge levels at varying load conditions. The second objective is to analyse and discuss models for an adjustment of the operation cycle for the SBR plant at varying, seasonal loads.

\section{Materials and Methods}

Operation data from spring 2012 to February 2013, obtained from the SBR plant in Kungsberget, have been used.

The following sources of information have been examined:

- Design data for the plant provided by the contractor, Milio och Bioteknik AB, Sweden

- Laboratory analysis on influent and effluent water during the period mentioned. Laboratory analyses have been performed by Eurofins, Sweden, a laboratory with accreditation from Swedish authorities

- Analyses of grab samples on $\mathrm{pH}$ and phosphorus performed at the plant, mainly on treated water.

- Operation data from the day-to-day operation of the plant

- For the SBR-performance a special study has been conducted as Master Thesis, Bercoff (2013).

The methods of analysis employed are as follows:

- For $\mathrm{BOD}_{7}$ SS EN 1899, including nitrification inhibitor, accuracy in analysis result $\pm 30 \%$;

- For TOC SS EN 1484 a, accuracy in analysis result $\pm 20 \%$;

- For Total P SS-EN ISO 15681 -2:2005/ a, accuracy in analysis result $\pm 10 \%$;

- For total Nitrogen SS-EN ISO 1 1905-1, accuracy in analysis result $\pm 10 \%$;

- For NH4-N SS-EN ISO 11732:2005 / Kone, accuracy in analysis result $\pm 15 \%$.

- For Suspended solids, SS, SS EN 872-2, accuracy in analysis result $\pm 10 \%$.

The plant is operated as a single batch reactor with simultaneous precipitation by adding an alum salt (PAX 21 - Poly Aluminium Chloride). The process configuration is shown in a simplified process scheme in Figure 1. The basic design data for the plant are presented in Table 1.

In order to estimate the (Mean) Solids Retention Time (SRT) for the SBR-system a simplified model is used. The model is based on the following assumptions:

1. The withdrawal of waste activated sludge (WAS) takes place during the phase called "React", meaning that the reactor is treating the full batch and the volume is aerated;

2. During the react phase the SS-concentration is homogenous throughout the reactor;

3. When the withdrawal of WAS takes place the SRT is principally directly related to the lowering of the liquid level in the reactor;

4. At the same time it is assumed that the SS-concentration in the decanted water is insignificant in comparison with the SS-

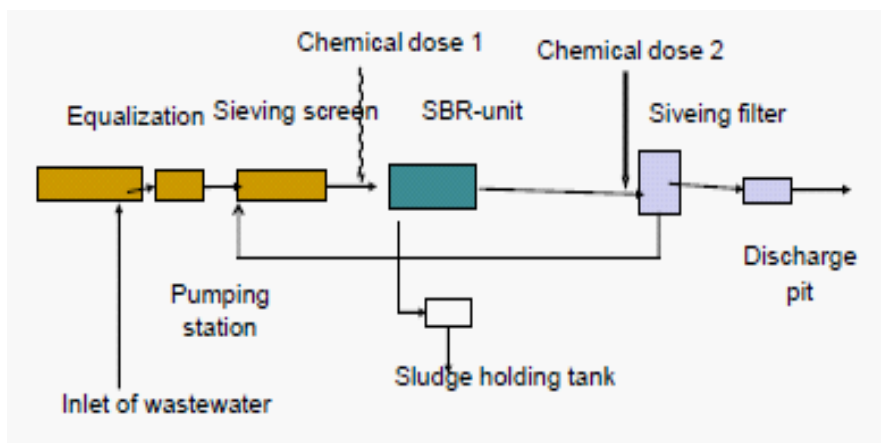

Figure 1. Simplified flow chart of the wastewater treatment plant in Kungsberget. 
amounts removed through the WAS flow;

5. Thus a simplified model is used: $S R T=H_{\text {max }} / \Delta h$, where

$H_{\text {max }}=$ Maximum level in reactor, in $\mathrm{cm}$;

$\Delta h=$ Daily lowering of the level in the reactor during react, due to wasting of activated sludge, in $\mathrm{cm}$

As an example: If $H \max =500 \mathrm{~cm}$ and $\Delta \mathrm{h}=50 \mathrm{~cm}$ the SRT is 10 days.

Table 1. Basic design data for the wastewater treatment plant in Kungsberget (Data from the contractor).

\begin{tabular}{lll}
\hline Spec. & Value & Unit \\
\hline Design flow & 100 & $\mathrm{~m}^{3} / \mathrm{d}$ \\
$\begin{array}{l}\text { Pollution load figures } \\
\text { BOD }_{7}\end{array}$ & 42 & \\
COD & 100 & $\mathrm{~kg} / \mathrm{d}$ \\
Total P & 1.12 & $\mathrm{~kg} / \mathrm{d}$ \\
Plant capacity figures & & \\
Sieving screen & & $\mathrm{m}^{3} / \mathrm{h}$ \\
SBR-unit & 108 & $\mathrm{~m}^{3}$ \\
Sieving filter unit & 60 & $\mathrm{~m}^{3} / \mathrm{h}$ \\
\hline
\end{tabular}

\section{Results and Discussion}

The results are presented below, divided into three operation periods:

- The first period covering winter and spring 2012. The period may be seen as a start-up period running from February to the end of April 2012

- The second period runs from August to the end of October 2012

- The third period covers January and February 2013

The prevailing wastewater temperatures lie between 12 and $15^{\circ} \mathrm{C}$. The small pipeline system and the limited leakage into the pipes explain these fairly high and stable temperatures.

An important observation when looking into the results presented below is that the sampling always includes sampling downstream the sieving filter unit. Thus, an improved removal of suspended matters is secured. On the other hand are the results and the discussion regarding the Solids Retention Time valid, as the back wash water from the filter is recycled into the SBR treatment stage.

\section{Flow Variations}

Recorded flows during the entire operation - from April 2012 through February 2013 are presented in Figure 2, showing the daily amounts of treated wastewater at the plant.

The flow makes up a pattern demonstrating two peak periods, connected to the "winter holidays" in Sweden, normally from February through April, ending at Easter each year.

During start up conditions the treated water flow exceeded the design flow $\left(100 \mathrm{~m}^{3} / \mathrm{d}\right)$ at some occasions.

\section{m3 Flow}

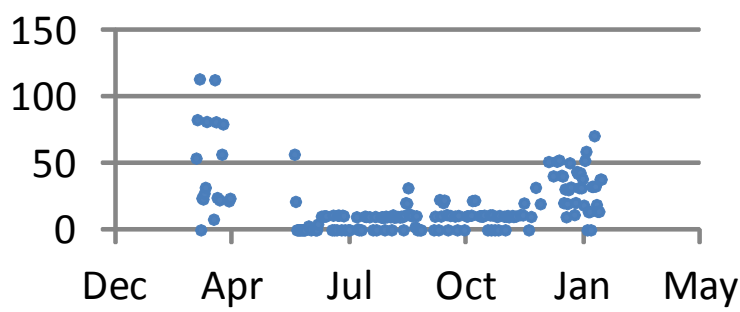

Figure 2. Recorded daily flows treated at the wastewater treatment plant in Kungsberget, Feb 2012 to March 2013.

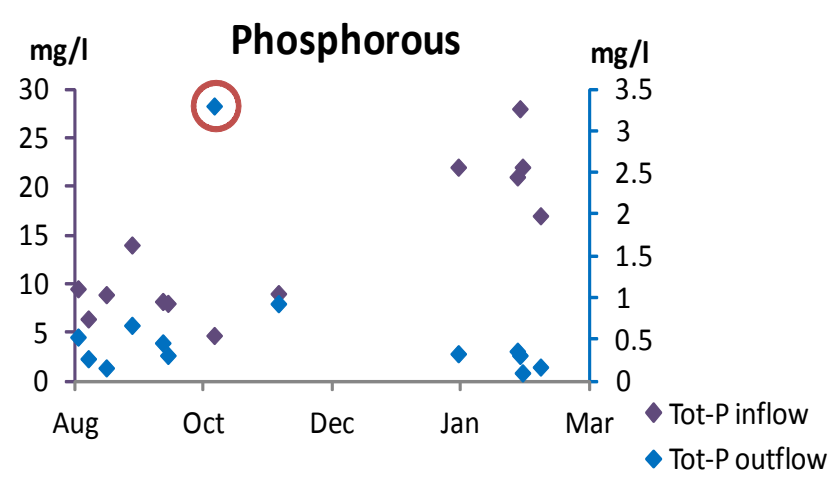

Figure 3. Inflow and outflow concentrations of P-tot The inflow concentrations are on the primary $y$-axis and the outflow concentrations on the secondary y-axis. The circled point is a suspected sampling error (Bercoff 2013).

The following year (2013) the maximum flows were in the vicinity of $50-70 \mathrm{~m}^{3} / \mathrm{d}$. On the other hand the pollution loading was even higher than the design levels during this situation, see further comments below.

\section{Pollution Loading and Discharge Results}

As the discharge level of phosphorus has been the most critical part of the performance, the results of the P-removal are discussed first. In Figure 3 the inlet and discharge levels of phosphorus at the plant throughout the operation period are shown.

A number of important observations may be drawn from the figure:

- During the second observation period, August to November 2012 , P-removal has been rather modest, with a far from acceptable discharge level of total $P$, predominantly $>0.5$ ppm. The corresponding percentage removal has been insufficient, accordingly, seldom reaching over $90 \%$.

- The modest P-removal coincides with a low load situation during the second period

- The discharge levels of phosphorus in February 2013 are substantially lower, in the vicinity of $0.3 \mathrm{mg} P / \mathrm{I}$, in spite of remarkably higher inlet $\mathrm{P}$-concentrations.

The most likely answers to the changes in phosphorus dis- 
charge levels may be attributed to a couple of circumstances:

- The relation between total $P$ and $S S$ in the discharge is normally found to be around 0.045: 1 with some variation. By addressing this ratio to the discharge levels of SS it may be possible to predict the needed discharge SS-concentration to maintain a P-level in the discharge at $<0.3 \mathrm{mg} \mathrm{P} / \mathrm{I}$. It is, however, also important to address the soluble part of $P$ in the discharge. During the second period (August through October 2012) the recorded levels of PO4-P were as shown in Table 2. These values may with some simplification be seen as the soluble part of $P$. This in turn points out two important conditions: the need for efficient chemical precipitation on one hand, and at the same time also the need for an excellent separation of suspended solids.

During the second period it was not possible to meet the effluent standards with respect to $P$. The discharge level of SS was around $14 \mathrm{mg} / \mathrm{l}$, and the total $P$ discharge was as on average around $0.5 \mathrm{mg} / \mathrm{l}$. The phosphate level was on average from 0.83 to $0.23 \mathrm{mg}$ PO4-P/l. An improved separation of SS alone

Table 2. Recorded discharge levels of PO4-P from the plant, August through October 2012.

\begin{tabular}{lllll}
\hline Month & August & September & October & \\
\hline Spec. & Value & Value & Value & Unit \\
\hline Nos of obs & 25 & 11 & 13 & $\mathrm{nos}$ \\
Max. value & 1.30 & 1.10 & 1.00 & $\mathrm{mg} \mathrm{P} / \mathrm{I}$ \\
Mean value & 0.83 & 0.41 & 0.23 & $\mathrm{mg} \mathrm{P} / \mathrm{l}$ \\
Median value & 0.87 & 0.3 & 0.17 & $\mathrm{mg} \mathrm{P} / \mathrm{l}$ \\
Minima value & 0.080 & 0.040 & 0.020 & $\mathrm{mg} \mathrm{P} / \mathrm{l}$ \\
\hline
\end{tabular}

would not be sufficient to reach the stipulated consent value of $0.3 \mathrm{mg} \mathrm{P} / \mathrm{I}$. It was evident that an adjustment to the chemical precipitation would be required. Through an increase of the chemical dose implemented at the beginning of 2013 by around $40 \%$ (see Bercoff 2013), it was possible to reach the stipulated discharge level of $0.3 \mathrm{mg} \mathrm{P} / \mathrm{I}$ during the final performance test. At the same time the settling and decant properties were substantially better, as the final effluent quality with respect to SS went from around 13 to $3 \mathrm{mg} \mathrm{SS} / \mathrm{I}$. It is especially worth noting that the total $P$ and the SS load levels were close to, or even above the design load levels during February 2013.

The performance with respect to organic pollution has shown different patterns throughout the operation. In Figure 4 the development of the COD-discharge concentrations during the three periods is shown. The high discharge levels during start-up are in the range of what can be considered normal. However, from May 2012 (figures from May to August are not recorded in Figure 4) the discharge levels are reduced from around $65 \mathrm{mg}$ $\mathrm{COD} / \mathrm{I}$ to $40 \mathrm{mg}$ COD/I in February 2013. It is striking that the improvement takes place even though the loading increases substantially. Loading levels at around $5 \mathrm{~kg} \mathrm{COD} / \mathrm{d}$ to $>100 \mathrm{~kg} / \mathrm{d}$ have occurred during the period. This development suggests that the removal of organic matters has greatly improved. The fact should be attributed to a stabilized and sufficiently high total
Solids Retention Time, see further in the following section. The same pattern is also clearly demonstrated when looking at the BOD7 discharge figures: the discharge levels have consistently been $<5$ ppm, from the beginning of June 2012 and throughout February 2013. At the same time, loading has increased by 20 fold during the final performance test period, compared with the low season loading.

Although nitrogen performance has not been subject to a permit restriction both nitrogen conversion and removal has been studied. The balance between total nitrogen (Tot N), ammonia nitrogen $\left(\mathrm{NH}_{4}-\mathrm{N}\right)$ and oxidised nitrogen $\left(\mathrm{NO}_{3}-\mathrm{N}\right)$ may be discussed only for the performance recorded from August 2012

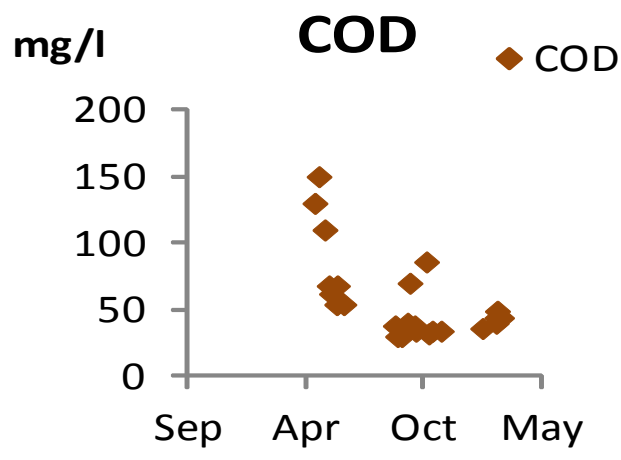

Figure 4. Results from Eurofins of COD concentration in effluent from April 2012 through February 2013 (after Bercoff 2013).

to the end of February 2013. Nitrates have not been analysed separately, thus the following assumption has been established to assess the degree of nitrification.

The total nitrogen discharge level is reduced by the corresponding ammonia nitrogen level, and further by $2 \mathrm{mg} \mathrm{N} / \mathrm{l}$ as "inert organic nitrogen". By using in all nine observations from end of August 2012 the following pattern may be found. A partial nitrification has been calculated, with typical discharge levels ranging from 15 to $44 \mathrm{mg} \mathrm{NO}-\mathrm{N} / \mathrm{l}$. The corresponding conversion efficiencies of the nitrogen compounds have varied between 49 and $62 \%$. The results also demonstrate a successive improvement of the discharge levels, as demonstrated in Figure 5. The improved nitrogen conversion and removal level is linked to the fundamental micro-biological conditions given by a sufficiently high SRT, enough oxygen supplied during the aeration phase and the prevailing water temperature, around $12{ }^{\circ} \mathrm{C}$.

However, these results do not cover any impact from a possible denitrification process. This process is governed by available organic carbon in the wastewater. By comparing the inlet values of COD and total $\mathrm{N}$ and calculating the ratio COD: Tot $\mathrm{N}$, it is possible to assess a potential denitrification level. The results are presented in Figure 6.

The ratio COD: $\mathrm{N}$-tot is by far below or substantially below what is normally found in raw municipal wastewater. The normal ratio is around 10:1. This in turn means that the denitrification potential may be somewhat limited.

A further control of the plant performance is to analyse the classical processing loading values, such as the F/M-ratio, ex- 


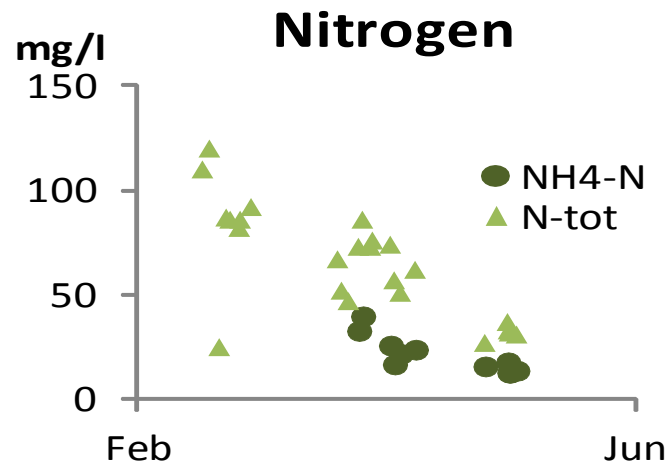

Figure 5. Results from Eurofins of total nitrogen and ammonium effluent water concentrations, May 2012 to the end of February 2013 (after Bercoff 2013).

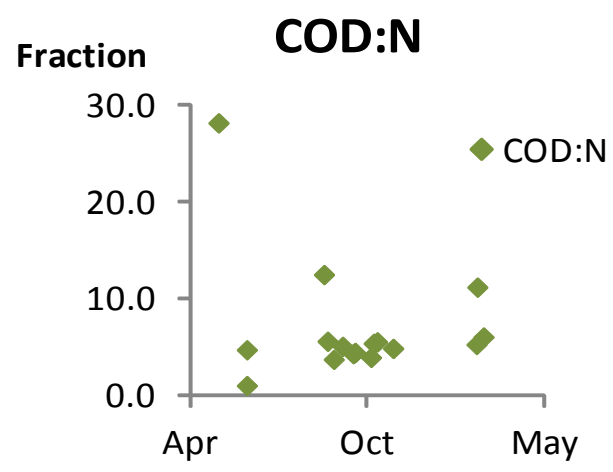

Figure 6. COD: $\mathrm{N}$-tot relationship in influent raw water, May 2012 to the end of February 2013 (after Bercoff 2013).

pressed as $\mathrm{kg} \mathrm{BOD} / \mathrm{kg} \mathrm{MLSS} / \mathrm{d}$, the specific nitrogen loading, expressed as $\mathrm{kg} \mathrm{N} / \mathrm{kg} \mathrm{MLSS} / \mathrm{d}$ and the SRT, both totally and the "aerated SRT". These values are applied to the loading situation in February 2013. The prevailing MLSS-concentration in the reactor is around $2.5 \mathrm{~kg} / \mathrm{m}^{3}$. The total reactor volume is 108 $\mathrm{m}^{3}$. A summary of the results from the February 2013 shows the following; see Table 3.

The SRT during the February test period have been calculated: The total SRT was found to be 15 days, while the "aerated SRT" was six days.

\section{Conclusions}

The one year operation of the SBR-facility at Kungsberget ski resort area has demonstrated some important features:

- It is possible to operate an activated sludge unit at very low loading conditions for an extended time with acceptable results;

- The SBR-system has responded very positively to a relatively rapid increase in pollution loading;
- The removal levels have been even better during the "full loading conditions" than during the low load periods;

- The typical performance results comply with a substantial margin for organic pollutants, such as $\mathrm{BOD}_{7}$ and $C O D_{\text {; }}$

- It is imperative to maintain a very low level of suspended solids in the effluent: a downstream filtration stage was necessary to fulfil the requirements on P-removal efficiency;

- When a removal level with respect to $P$ is $>97 \%$ it is essential to control the chemical precipitation closely;

- Finally, it was possible to achieve nitrification, probably in this case limited by the operated "aerated SRT" and the supply of oxygen.

\section{Acknowledgements}

The authors want to express the gratitude to the owner of the plant, Kungsberget Ski Resort, and especially the responsible staff for operation of the plant. Accordingly the contractor, Bioteknik och Miljö, Sweden has provided support and information regarding design and has also delivered the analysis results from the laboratory.

\section{References}

Abufayed AA and ED Schroeder (1986) Kinetics and stoichiometry of $S B R /$ denitrification with a primary sludge carbon source. Journal WPCF 58 (5): 398-405.

Barth E (1981) Sequencing Batch Reactors For Municipal Wastewater Treatment. Paper presented at the 8th United States/Japan Conference on Sewage Treatment Technology. Cincinnati, Ohio. pp $1-27$.

Bercoff A (2013) "Investigation of the treatment process at Kungsberget's wastewater treatment plant under periods of irregular and low loads" Copyright (C) Alexandra Bercoff and Department of Information technology, Uppsala University. UPTEC W 13010, ISSN 1401-5765. Published digitally at the Department of Earth Sciences, Geotryckeriet, Uppsala University, Uppsala, 2011.

Berg J and S Morling (2013) Process Adaption and Modification of a Nutrient Removing Wastewater Treatment Plant in Sri Lanka Operated at Low Load Conditions. Material Sciences and Applications 4: 299 - 306, http//www.scirp.org/journal/msa.

Marklund S and S Morling (1994) Biological phosphorus removal at temperatures from 3 to $10^{\circ} \mathrm{C}-$ a full-scale study of a sequencing batch reactor unit. Can. J. Civ. Eng. 21: 81-88.

Morling S (2001) Performance of an SBR-plant for advanced nutrient removal, using septic sludge as a carbon source. Water, Science and Technology 43 (3): 131-138.

Morling S (2009) SBR-technology - use and potential applications for treatment of cold wastewater. Doctoral Thesis in Land and Water Resources Engineering, Stockholm, Sweden 2009, ISBN 978-917415-341-5.

Morling S (2010) Nitrogen removal and heavy metals in leachate treatment using SBR technology. Journal of Hazardous Materials 174 (1-3): 679-86.

Pasveer A (1959) A Contribution to the Development in Activated Sludge Treatment. Journal of WPCF 449-465. 